\title{
Starting Conversations on Visual Media and Global Learning
}

\author{
Danilo M. Baylen ${ }^{1} \cdot$ Brad Hokanson ${ }^{2}$ \\ Published online: 18 August 2021 \\ (C) Association for Educational Communications \& Technology 2021
}

\section{Introduction}

Putting together a special section for a publication like TechTrends is always a challenge. As a journal for ideas, research, and practices involving instructional technology, TechTrends is the first choice for many emerging and experienced authors. The editorial and publication process involved solicitation, proposal review and feedback, mentoring, and editing. Each of these steps can be complex. The coeditors of the special section focusing on visual media and global learning for TechTrends are no strangers to the challenges.

How we see is essential to understanding the world and particularly to how we communicate and educate. The visual remains vital in a text or the data-dominated world that often gets neglected to understand learning and thought. Here are explorations and research on the visual aspects of learning. This special section illuminates the range of ideas present with visual literacy for the broad field of educational technology.

\section{Submission}

For this particular section on visual literacy, soliciting participation involving proposal submission of actual manuscripts was the first hurdle for the coeditors. They entertained initial inquiries and encouraged proposal submissions. Some of these proposals were fully written, while others were developed from initial writing exercises. With the initial submissions, the recruitment of reviewers to identify proposals with

Danilo M. Baylen

dbaylen@westga.edu

Brad Hokanson

brad@umn.edu

1 University of West Georgia, Carrollton, GA, USA

2 University of Minnesota - Twin Cities, Minneapolis, MN, USA potential for publication in the special section was critical. Potential authors subsequently received feedback from peer reviews after putting together a full manuscript.

\section{Review}

The distance between a proposal and a manuscript can be daunting to many authors, especially those submitting for TechTrends the first time. As a journal focusing on educational technology, the expectations are pretty straightforward. However, the special section's focus on visual literacy requires balancing the journal goals and the field of study. This act requires submitted manuscripts be forwarded to at least three reviewers of diverse but relevant backgrounds for feedback. For this process, the reviewers used four criteria items for the review:

1. Appropriateness for the TechTrends special section on Visual Media and Global Learning. The manuscript aligns with the goal of the special section in addressing the importance of visual literacy in the context of using and integrating technology to support teaching, learning, or research activities.

2. Contribution to visual literacy scholarship. The manuscript focuses on innovative ideas or best practices on Visual Literacy and Internet Communications Technology, Media Literacy, Visual Communication, etc.) in using and integrating educational technology.

3. Appropriate application of visual or media literacy. The manuscript demonstrates the appropriate application of theory, pedagogy, or concepts relevant to visual or media literacy and visual communication.

4. Quality of writing appropriate for both academicians and practitioners. The manuscript demonstrates good organization, clarity, style, etc., and uses the third person.

The reviewers reviewed and evaluated the submitted manuscripts given the criteria for publication and rated the 
proposed work as accept, minor revisions, and significant editorial work or reject.

\section{Mentoring}

The coeditors engaged the authors in revising their manuscripts. With the abundance of experience using virtual meeting applications such as Zoom or Google Meet, the coeditors met with the authors and discussed the feedback from peer reviewers. Authors received written and verbal feedback during these virtual meetings. At least two or more virtual meetings took place between coeditors and authors on all manuscripts.

The coeditors believe in mentoring young scholars writing for the field of visual literacy. Given the coeditors' background, they have seen many potential authors for TechTrends write well on technology use or practices. However, the integration of visual literacy in the manuscripts was limited and needed more expanded coverage to not read like an add-on or afterthought.

\section{Outcomes}

After receiving multiple feedback and revisions to each manuscript, the coeditors accepted six articles demonstrating visual literacy application in technology-rich learning contexts. In reviewing the content of these manuscripts, three themes emerged from 1) Demonstrating visual literacy knowledge and skills in teaching contexts, 2) Application of visual literacy in generating new knowledge, and 3) Application of visual literacy in global learning contexts.

Two articles by Lauren Eutsler and Taralynn Hartsell focused on demonstrating visual literacy knowledge and skills in teaching contexts. In Making Space for Visual Literacy in Literacy Teacher Preparation: Preservice Teachers Coding to Design Digital Books, Eutsler explored preservice teachers' coding experiences in designing visually-enhanced digital books. Hartsell's article, Visualization of Knowledge with Concept Maps in a Teacher Education Course, described how concept maps become practical visual tools for instruction. Both pieces provided insights using technology-based tools and demonstrated how visualization could support student engagement.
Other authors wrote articles focusing on applying visual and media literacy to generate new knowledge. Craig Howard's paper, Participatory Media Literacy in Collaborative Video Annotation, described and discussed an application that facilitated different ways of seeing the interplay of images, text, and learner choices. Abigail Winard, Simane Aboulkacem, and Lory Haas wrote about an application called Photovoice. In their article titled, Photovoice 2.0: A Comprehensive Research Framework for the Digital Generation, the authors discussed one's ability to navigate digital platforms with enhanced skills in taking and analyzing photographs and articulating the deeper meaning of the images for purposeful social change.

The final two articles written by Suzanne Ensmann and Eman Alshawaf focused on visual literacy in global learning contexts. Both pieces covered teaching and learning practices outside of the United States. Ensmann's report, Digital Games to Improve Learning in Haiti, covered her inquiry on designing a service-learning case for children. Alshawaf interviewed image-makers from different parts of the world to share their social media experiences. In her article, iPhoneography as Visual Literacy: How Image-Making Practices on Social Media Encourage Creative Growth, she discussed new directions for studying visual literacy as a framework in examining the reading and making images.

\section{Moving Forward}

Visual literacy is an essential concept for anyone growing and living in the twenty-first century. The teaching and learning spaces have changed so much due to technology. In a visually rich world, both children and adults have a greater need to develop and demonstrate visual literacy skills and competencies. Visual literacy is not about seeing pretty pictures. It is about creating images or visuals. It is about an interpretation of what is seen around us every day or in different contexts. Finally, it is about communicating what we see and presenting meaning in speaking or writing ideas.

Publisher's Note Springer Nature remains neutral with regard to jurisdictional claims in published maps and institutional affiliations. 